\title{
No limite do psíquico e do legal: a transgeracionalidade em processos de destituição do poder familiar
}

\author{
Recebido: 08 de agosto de 2017 • Aprovado: 08 de outubro de 2018 \\ https://doi.org/10.22395/ojum.v18n36a9 \\ Mariana Datria Schulze"* \\ Aline Cristine de Moura Alves ${ }^{* * *}$
}

\begin{abstract}
RESUMO
O processo de Destituição do Poder Familiar envolve crianças ou adolescentes em situações de risco, de abandono e de violência intrafamiliar, uma vez que se deixa de cumprir com o que prevê o Estatuto da Criança e do Adolescente brasileiro. Diante desse contexto, o Estado intervém na família e instaura o processo contra os pais, ou seja, eles correm o risco de perder o poder familiar sobre seus filhos. A partir disso, este estudo buscou compreender quais aspectos da transmissão psíquica transgeracional se fazem presentes no desempenho do papel parental de pais e mães que estavam na eminência de perder a guarda de seus filhos. Este estudo tem como metodologia a pesquisa documental e usa como objeto processos judiciais de Destituição do Poder Familiar referente aos anos de 2010 a 2015 da Vara da Infância da Comarca de Joinville, o que totaliza nove processos. Com a análise dos laudos psicológicos e dos estudos sociais produzidos para os processos judiciais de destituição do poder familiar, constatou-se indícios da transmissão psíquica transgeracional, especificamente quanto às formas de violência intrafamiliar e ao processo de negligência afetiva presentes na história pregressa desses pais e mães.
\end{abstract}

Palavras-chave: destituição do Poder Familiar; transgeracionalidade; violência intrafamiliar.

Projeto de Pesquisa intitulado "Entre o limite do psíquico e do legal: a transmissão psíquica transgeracional em processos de destituição do poder familiar", Mariana Datria Schulze, Orientadora, Universidade da Região de Joinville (Univille), Brasil, 2016.

* Psicóloga, Universidade da Região de Joinville, Joinville, Brasil. Especialista em Interdisciplinaridade, Universidade da Região de Joinville, Joinville, Brasil. Mestra em Educação, Universidade da Região de Joinville, Joinville, Brasil. Doutoranda em Educação, Universidade Federal de Santa Catarina, Florianópolis, Brasil. Professora e pesquisadora, Universidade da Região de Joinville, Joinville, Brasil. Professora, Faculdade Ielusc, Joinville, Brasil. E-mail: m.schulze@univille.br

*.* Psicóloga, Universidade da Região de Joinville, Joinville, Brasil. E-mail: aline.alvees@gmail.com 


\title{
At the limit of the psychic and the law: transgenerationality in family loss of custody cases
}

\begin{abstract}
The process for removal of the Family Power withdraw legal authority from careless parents involves children and adolescents in situations of risk, of abandonment, and of domestic violence, as it fails to comply with the Brazilian Statute of Children and Adolescents. In this context, the State intervenes in the family and institutes this process against the parents, that is, the risk of losing legal authority over their children. This study sought to understand what aspects of transgenerational psychic transmission are present in the performance of the parental role of fathers and mothers who were in the eminence of losing custody of their children. This study's methodology is document research, with the research of legal authority processes between the years 2010-2015 of Joinville County, totaling nine processes. With the analysis of the psychological reports and social studies produced for the judicial processes of withdraw legal authority, evidence of the transgenerational psychic transmission was verified, specifically regarding the forms of intrafamily violence and the process of affective negligence present in the previous history of these parents.
\end{abstract}

Keywords: Removal of the Family Power; transgenerationality; intrafamily violence.

\section{En el limite del psíquico y del legal: la transgeneracionalidad en procesos de destitución del poder familiar}

\section{RESUMEN}

El proceso de Destitución del Poder Familiar involucra niños o adolescentes en situaciones de riesgo, de abandono y de violencia intrafamiliar, una vez que no se cumple con lo previsto en el Estatuto del Niño y del Adolescente brasileño. En ese contexto, el Estado interviene en la familia e instaura el proceso contra los padres, es decir, ellos están en riesgo de perder el poder familiar sobre sus hijos. A partir de eso, este estudio buscó comprender cuales aspectos de la transmisión psíquica transgeneracional están presentes en el desempeño del rol parental de padres y madres que han estado en la eminencia de perder la custodia de sus hijos. Este estudio tiene como metodología la investigación documental y usa como objeto procesos judiciales de Destitución del Poder Familiar, referente a los años de 2010 a 2015 de la Jurisdicción de la Infancia de la Comarca de Joinville, lo que ha totalizado nueve procesos. Con el análisis de los laudos psicológicos y de los estudios sociales producidos para los procesos judiciales de destitución del poder familiar, se ha constatado indicios de la transmisión psíquica transgeneracional, específicamente con respeto a las formas de violencia intrafamiliar y al proceso de negligencia afectiva presentes en la historia anterior de esos padres y madres.

Palabras clave: Destitución del Poder Familiar, transgeneracionalidad, violencia intrafamiliar. 


\section{INTRODUCÃO}

O processo de Destituição do Poder Familiar é a sanção mais grave relacionada ao exercício do papel parental para os pais que não assegurem os direitos da criança ou adolescente envolvido, conforme previsto no Estatuto da Criança e do Adolescente (ECA). A respeito das circunstâncias que envolvem a dinâmica familiar dos processos de Destituição do Poder Familiar, trata-se de um cenário em que sujeitos menores de idade encontram-se em situações de abandono.

Segundo Tostes (2007), para o Direito, o abandono está relacionado ao exercício do Poder Familiar, ou seja, o cumprimento ou não das obrigações legais perante o filho. O abandono se caracteriza pelo desinteresse dos pais em relação ao filho, que não proporcionam devida assistência a esse, negando e privando-o de apoio moral e material.

Conforme a mesma autora, para a Psicologia, por intermédio da Psicanálise, o sujeito é compreendido através de sua dimensão subjetiva. Posto isso, o abandono é compreendido a partir de uma construção complexa da relação entre o sujeito e seu ambiente. $\mathrm{O}$ abandono não se caracteriza apenas pela negligência física, mas também, pelo desamparo emocional e afetivo na relação pais-filho. Nesse sentido, a relação de abandono analisada na condução desta pesquisa contempla a ausência, o descaso e o desapego nos sentidos físicos, emocionais e afetivos entre progenitores e seus descendentes.

A Destituição do Poder Familiar envolve demandas das formas de violência intrafamiliar e de abandono, vivenciadas pela criança e/ou adolescente em sua família. O que se percebe, a respeito da dinâmica familiar, de acordo com os estudiosos da transgeracionalidade é que existe a repetição de histórias pregressas das famílias, transmitidas ao longo das gerações futuras (Lemaire, 2003). Dessa forma, o indivíduo poderá cometer, em sua relação familiar, a repetição daquilo que foi herdado sem a possibilidade de elaboração. Partindo disso, surge a problemática da transmissão psíquica transgeracional, que contribui para a constituição da subjetividade do sujeito diante do que é herdado.

Entende-se essa conturbada relação familiar pelas características de um processo de perpetuação da violência intrafamiliar, assim como influências ímpares no processo de constituição psíquica do sujeito. De tal modo, torna-se relevante identificar a possível reprodução do comportamento e da dinâmica familiar, e considerar o impacto dessa transmissão na constituição psíquica das crianças e adolescentes que vivenciam as situações de risco em seu ambiente familiar. 
Esta pesquisa partiu do interesse em compreender a complexidade que envolve os processos de Destituição do Poder Familiar. A partir da vivência em um estágio no Serviço Psicossocial do Fórum da Comarca de Joinville, as pesquisadores tiveram contato com a realidade dos referidos processos, o que instigou a realização da investigação. Importante esclarecer que a proposta foi aceita pela equipe do Serviço Psicossocial e autorizada pelo excelentíssimo Juiz de Direito da Vara da Infância, o que possibilitou que as pesquisadoras tivessem acesso aos processos judiciais que correm em segredo de justiça e aos documentos sigilosos que os compõe. Nesse sentido, esta investigação pretendeu compreender quais fatores referentes à transmissão psíquica transgeracional se fazem presentes no desempenho do papel parental em casos de Destituição do Poder Familiar.

\section{FUNDAMENTACÃO TEÓRICA}

Nas últimas décadas vem sendo construído um diálogo importante e que se faz necessário entre a Psicologia e o Direito. Segundo Silva (2003), "esse fenômeno deriva de uma necessidade, cada vez mais crescente, de se redimensionar a compreensão do agir humano, à luz dos aspectos legais e afetivo-comportamentais" (p. 7).

Em relação à justiça, essas duas ciências têm o mesmo objeto de estudo, porém com olhares particulares e diferenciados sobre ele. O Direito está atrelado à questão legal e a Psicologia à questão subjetiva dos indivíduos envolvidos no conflito, conforme compreende Huss (2011), "o direito e a psicologia também diferem, pois, enquanto a psicologia é descritiva, o direito é prescritivo. A psicologia descreve o comportamento humano e o direito dita ou prescreve como os humanos devem se comportar" (p. 33). Desse modo, ambos os olhares se fazem necessários e complementares para se atingir uma maior compreensão do processo judicial em prol da justiça.

Entende-se que a Psicologia Jurídica coloca à disposição do juiz seus conhecimentos, o que contribui no processo judicial com uma compreensão psicológica que ultrapassa a lei, um trabalho que vai além da exposição dos fatos e humaniza o judiciário na construção do ideal de justiça.

Entre as possibilidades e realizações profissionais na intersecção da Psicologia e do Direito encontram-se os processos de Destituição do Poder Familiar. Para a compreensão de tais casos, é importante retomar aspectos pontuais no que diz respeito aos Direitos da Criança e do Adolescente, do mesmo modo como as práticas parentais que permeiam o Poder Familiar envolvidas nesses processos.

No que se refere aos Direitos da Criança e do Adolescente, estes estão dispostos no Estatuto da Criança e do Adolescente (ECA), que prevê seus direitos fundamentais, 
quais sejam: à vida e à saúde; à liberdade, ao respeito e à dignidade; à convivência familiar e comunitária; à educação, à cultura, ao esporte a ao lazer; e à profissionalização e à proteção no trabalho (Brasil, 2014).

Especificamente sobre as questões relacionadas ao direito à convivência familiar e comunitária expostos no ECA, segundo o artigo 190, "toda criança ou adolescente tem direito a ser criado e educado no seio da sua família e, excepcionalmente, em família substituta, assegurada a convivência familiar e comunitária, em ambiente livre da presença de pessoas dependentes de substâncias entorpecentes" (Estatuto da Criança e do Adolescente, 2014, p. 19). Ou seja, conforme estabelecido pelo ECA, a convivência familiar que ocorre no seio da sua família natural ou em família substituta, na modalidade de guarda, tutela ou adoção, é uma prerrogativa imprescindível.

Como é possível perceber, os direitos da criança e do adolescente estão atrelados ao Poder Familiar, sendo que este, por sua vez, baseia-se no entendimento de tal poder como um conjunto de responsabilidades e deveres designados aos pais em prol do desenvolvimento saudável do filho, já que, conforme Dias (2006) é dever dos pais a ser exercido no interesse do filho.

Segundo Pereira (2004), o poder familiar apresenta as seguintes características:

(...) é "indisponível", no sentido de que o pai não pode abrir mão dele; é "inalienável", quer dizer, não pode ser transferido; é "irrenunciável", e incompatível com a transação; é "imprescritível", vale dizer, que dele não decai o genitor pelo fato de deixar de exercitá-lo. Somente podem perdê-lo os pais na forma de lei (p. 423).

Diante do exposto, encontra-se o Estado Moderno, instituição legitimada a intervir no âmbito familiar para defender os interesses dos menores, quando um ou ambos os genitores deixam de cumprir com seus deveres mantendo um comportamento que possa vir em prejuízo do filho.

De acordo com Torres et al. (2012), o Estado, por meio do Ministério Público, instaura ação de Destituição do Poder Familiar a fim de preservar a integridade física e psíquica da criança ou adolescente. A Destituição ou perda do Poder Familiar é o fim do exercício do Poder Familiar por decorrência do que está elencado no Código Civil, pelo artigo 1638 (Código Civil Brasileiro e legislação correlatada, 2008), em que se descreve: "perderá por ato judicial o poder familiar o pai ou a mãe que: i) castigar imoderadamente o filho; ii) deixar o filho em abandono; iii) praticar atos contrários à moral e aos bons costumes; iv) incidir, reiteradamente, nas faltas previstas no artigo antecedente" (p. 352). 
Nesse contexto, com a exposição de crianças e adolescentes às situações de risco, uma possível medida é o acolhimento institucional. Quando o Ministério Público, pela figura do Promotor de Justiça, depara-se com a situação de institucionalização da criança ou do adolescente, devido à negligência, à omissão ou ao abuso relacionado às práticas parentais, prioriza-se buscar uma solução que melhor atenda aos interesses da criança/adolescente em tela. De acordo com Ferreira (2004), com a finalidade de uma definição dessa situação, para viabilizar o retorno da criança ao convívio familiar, seja na família de origem ou em consequência da Destituição do Poder Familiar sua colocação em família substituta.

O retorno da criança/adolescente para a família de origem se dá por meio de ações promovidas em conjunto com a família e o Poder Público, para que ocorram mudanças e sejam estabelecidas condições favoráveis ao retorno da criança/adolescente a seu lar, como discute Ferreira (2004). Portanto, garante-se o que está disposto no artigo $4^{\circ}$ do Estatuto da Criança e do Adolescente (2014),

É dever da família, da comunidade, da sociedade em geral e do poder público assegurar, com absoluta prioridade, a efetivação dos direitos referentes à vida, à saúde, à alimentação, à educação, ao esporte, ao lazer, à profissionalização, à cultura, à dignidade, ao respeito, à liberdade e à convivência familiar e comunitária (p. 14).

Em contrapartida, há genitores que não modificam ou não conseguem sustentar a mudança da dinâmica familiar e, consequentemente, entende-se o retorno à família de origem como prejudicial à criança/adolescente e, então, é sentenciada a Destituição do Poder Familiar.

Com base na dinâmica familiar existente nas ações de Destituição do Poder Familiar, faz-se relevante o estudo da transmissão psíquica transgeracional, ou seja, a transgeracionalidade, relacionada à família e como esta pode influenciar as práticas parentais. A partir de uma perspectiva psicanalítica, o conceito de transmissão proposto por Eiguer (1998) refere-se a "tomar conhecimento da realidade psíquica que se transporta, desloca-se ou transfere-se de um indivíduo a outro, entre eles ou através deles, ou nos vínculos do conjunto, ainda que a matéria psíquica transmitida se transforme ou permaneça idêntica nessa passagem" (p. 8).

É por meio das alianças inconscientes que acontece a transmissão, "o inconsciente de cada indivíduo leva a marca, na sua estrutura e nos seus conteúdos, do inconsciente de um outro, e mais precisamente, de mais de um outro" (Eiguer, 1998, p. 14). Aquilo que se é transmitido deixa uma marca na estrutura psíquica do indivíduo que, sem a possibilidade de elaboração, passará adiante e reproduzirá tal estrutura. 
A partir desse conceito de transmissão, o que se transmite é aquilo que não se lembra, como: a falta, a doença, a vergonha, o recalcamento, os objetos perdidos. Mas não é apenas o negativo que é transmitido, é também o que ampara e assegura as continuidades narcísicas, a manutenção dos vínculos, a conservação das formas e dos processos de conservação e a complexidade da vida. Dessa forma, o que é transmitido de um espaço psíquico a outro, sem possibilidade de elaboração, é denominado por "transmissão psíquica transgeracional" (Eiguer, 1998).

A transmissão psíquica transgeracional se refere à herança genealógica inconsciente e que é transmitida por várias gerações. De acordo com Rehbein e Chatelard (2013), ela ocorre por mecanismos de identificação e por investimento libidinal de representações fantasmáticas que vêm de uma forma de organização do psiquismo do indivíduo.

Segundo Piva (2006), Freud afirma que "as fantasias combinam o que é vivenciado com o ouvido, o passado da história dos pais e antecessores com o presenciado pelo próprio indivíduo" (p. 128). De tal modo, resulta que essa combinação — que envolve o singular e o transgeracional, que é transmitida transgeracionalmente-, convertese em uma trama fantasmática familiar, ou seja, o indivíduo não escolhe, sozinho, identificar-se com algum aspecto do pai, por exemplo, mas está inserido nessa trama pelo fato de pertencer à família.

Diante do exposto, a transmissão psíquica transgeracional se faz presente no âmbito familiar, visto que os indivíduos tendem a reproduzir e se apropriar de práticas, comportamentos, conceitos de seus antecessores, bem como é também constituinte da subjetividade do indivíduo.

Piva (2006) compreende a transmissão psíquica transgeracional como "possibilidade de compreensão do sujeito como herdeiro de múltiplas experiências ancestrais, que tanto o enriquecem quanto podem torná-lo prisioneiro de uma história que não é sua. Nesse sentido, vale enfatizar que a transmissão transgeracional é universal e coformadora de subjetividade" (p. 23).

Quando não se realiza um trabalho psíquico a respeito daquilo que é transmitido, quando não é feito um trabalho de elaboração, não se consegue transformar aquilo que recebe, como bem coloca Piva (2006), "quando o herdado é apenas acatado, sem elaboração, sem ligação, estamos no território da compulsão à repetição, da alienação. O herdado passa a ser, então, como um destino a cumprir" (p. 24).

Portanto, a transmissão psíquica transgeracional refere-se tanto ao que garante a continuidade narcisista e a manutenção de vínculos, ou seja, as formas estruturantes, 
quanto às formas desestruturantes da transmissão que se referem ao que é negativo, nomeado por Eiguer (1998) como "a parte maldita da herança". A transmissão pode tanto contribuir para a constituição de uma subjetividade promissora como pode desencadear uma reprodução de erros.

Existem dinâmicas familiares que correspondem às formas desestruturantes da transmissão psíquica transgeracional, e assim reproduzem os erros de seus antecessores e o sofrimento também. Para Santos (2007), "a multigeracionalidade da violência pode ser compreendida como a possibilidade de o adulto reproduzir com crianças da família as suas próprias experiências de violência vividas na infância" (p. 43).

Desse modo, diante das formas desestruturantes da transmissão psíquica transgeracional, torna-se imprescindível conceituar algumas formas de violência intrafamiliar que estão relacionadas às ações de Destituição do Poder Familiar.

Para Cesca (2004), a violência intrafamiliar é "toda ação ou omissão que prejudique o bem-estar, a integridade física, psicológica ou a liberdade e o direito ao pleno desenvolvimento de outro membro da família" (p. 41). Essas circunstâncias, quando envolvem uma criança ou adolescente, ferem o que está previsto no ECA. Nesse sentido, são esses os fatores de violência que permeiam as ações de Destituição do Poder Familiar, pois o lar que deveria ser sinônimo de proteção e segurança passa a ser a fonte de violência contra essa criança ou adolescente.

Segundo Day et al. (2003) existem quatro formas mais comuns de violência intrafamiliar: a física, a psicológica, a negligência e a sexual.

A violência física ocorre quando alguém causa ou tenta causar dano por meio de força física, de algum tipo de arma ou instrumento que possa causar lesões internas, externas ou ambas. A violência psicológica inclui toda ação ou omissão que causa ou visa a causar dano à autoestima, à identidade ou ao desenvolvimento da pessoa. A negligência é a omissão de responsabilidade de um ou mais membros da família em relação a outro, sobretudo àqueles que precisam de ajuda por questões de idade ou alguma condição física, permanente ou temporária. A violência sexual é toda ação na qual uma pessoa, em situação de poder, obriga à realização de práticas sexuais, utilizando força física, influência psicológica ou uso de armas ou drogas. (p. 10)

A violência contra crianças e adolescentes pode afetar todos os aspectos de sua vida, além de interferir na sua estrutura emocional e psicológica, no físico, no comportamental, no escolar, na sexualidade, na sua concepção de família, nas relações interpessoais, na espiritualidade e, ainda, na autoestima, e proporcionar o estímulo a uma possível ocorrência de violência subsequente (Day et al., 2003). 
Diante do exposto, é importante observar o quanto a Psicologia e o Direito podem caminhar lado a lado a fim de proporcionar uma melhor compreensão a respeito dessas situações no melhor interesse da criança e do adolescente.

É importante frisar que essa transmissão também constitui a subjetividade humana e esses ciclos de violência estão sendo vivenciados de gerações em gerações. A Psicologia pode contribuir para esse contexto, pois ela busca compreender os conflitos existentes a fim de auxiliar a família, se possível, ou ao menos a criança ou o adolescente envolvido no "legado" dessa transmissão.

Quando se trata das situações que levam o Poder Público a intervir em uma família por meio de ações como a Destituição do Poder Familiar, remete-se à um ciclo de violência intrafamiliar de diversos gêneros e graus. Pode-se tratar de famílias em que a transmissão do que foi herdado não foi elaborado e sim, reproduzido, sendo devastador o suficiente para submeter os filhos a situações de violências que diversas vezes foram vivenciadas pelos pais durante a infância. Portanto, caso o "legado" dessa transmissão permaneça, pode vir a ser reproduzido por seus filhos.

\section{PROCEDIMENTOS METODOLÓGICOS}

A presente pesquisa teve como objetivo compreender quais fatores referentes à transmissão psíquica transgeracional se fazem presentes no desempenho do papel parental em processos de Destituição do Poder Familiar.

Para o desenvolvimento da investigação, primeiramente o projeto da pesquisa foi aprovado pelo Comitê de Ética em Pesquisa por se tratar de documentos sigilosos. Assim, a pesquisa de tipo documental se apresentou como a mais coerente ao considerar como objeto de pesquisa os processos de Destituição do Poder Familiar, especificamente o laudo psicológico e o estudo social referente a cada caso. De acordo com Cellard (2008),

[...] o documento escrito constitui uma fonte extremamente preciosa para todo pesquisador nas ciências sociais. Ele é, evidentemente, insubstituível em qualquer reconstituição referente a um passado relativamente distante, pois não é raro que ele represente a quase totalidade dos vestígios da atividade humana em determinadas épocas. Além disso, muito frequentemente, ele permanece como o único testemunho de atividades particulares ocorridas num passado recente (p. 295).

A pesquisa documental é compreendida por dois momentos importantes que incluem a coleta de documentos e a análise do conteúdo obtido. A coleta dos documentos exige alguns cuidados e procedimentos técnicos acerca da aproximação 
do local em que se pretende realizar a "garimpagem" das fontes que lhes pareçam relevantes a sua investigação. Quanto a esse aspecto, a pesquisa desenvolvida e relatada neste artigo se concentrou em encontrar os processos de Destituição do Poder Familiar do período de 2010 a 2015 que consolidassem uma amostragem de acordo com os critérios de inclusão e exclusão, quais sejam: processos de Destituição do Poder Familiar da Comarca de Joinville, tendo sido realizado estudo psicossocial que inclui o laudo psicológico, referentes aos anos de 2010 a 2015 e em trâmite; famílias com o mínimo de dois filhos e o máximo de cinco filhos. Foram excluídos da amostra os processos encaminhados para outras Comarcas ou que estivessem sentenciados e arquivados, processos em que as partes não compareceram para a avaliação psicológica e com situações em que apenas um dos genitores estivesse sendo destituído do poder familiar.

A primeira consulta dos processos para verificação da amostra da pesquisa foi realizada através do Sistema para Consulta Processual (SAJ), que é um sistema utilizado pelo Tribunal de Justiça para a consulta dos processos. Tal consulta teve como objetivo fazer o levantamento da quantidade de processos de Destituição do Poder Familiar, existentes do ano de 2010 até o mês de julho do ano de 2015, que foi o momento em que foi realizado o levantamento dos processos. Essa consulta resultou em um total de 442 processos, sendo que apenas 87 deles estavam em trâmite. Então, de acordo com os critérios de exclusão da pesquisa, a amostra iniciou em 87 processos.

Após esse número decorreu-se a verificação dos demais critérios de inclusão e exclusão da pesquisa e concluiu-se que nove processos de ações de Destituição do Poder Familiar seriam analisados. É importante ressaltar que as partes do processo, por questões éticas e por segredo de justiça, tiveram seus nomes resguardados, sendo representados por mãe ou pai.

Vale ainda esclarecer que o percurso para se chegar aos nove processos incluiu uma análise mais pormenorizada dos documentos, na qual notou-se a necessidade de extinguir o critério de exclusão que delimitava o número de filhos por família devido à variação do número de crianças por família.

A pesquisa documental também contempla outro importante momento que é a análise dos dados colhidos. Para tanto, elegeu-se a análise de conteúdo que, conforme Bardin (1995) é "um conjunto de técnicas de análise das comunicações visando obter, por procedimentos, sistemáticos e objetivos de descrição do conteúdo das mensagens, indicadores (quantitativos ou não) que permitam a inferência de conhecimentos relativos às condições de produção/recepção (variáveis inferidas) destas mensagens" (p. 42). 
A partir de tal escolha metodológica, de acordo com Silva (2003), o pesquisador irá descrever e interpretar o conteúdo dos documentos buscando responder a problemática que motivou a pesquisa e, assim, contribuir para o conhecimento científico.

A análise dos resultados foi contemplada por duas fases em que foram feitas comparações e associações do material obtido na coleta de dados de acordo com o objetivo da pesquisa. Em vista disso, primeiramente, foi realizada a comparação do que resultou de cada processo, com o intuito de identificar pontos em comum no conteúdo.

A seguir foi realizada a etapa de categorização que "é uma operação de classificação de elementos constitutivos de um conjunto, por diferenciação seguida de um reagrupamento baseado em analogias, a partir de critérios definidos" (Franco, 2008, p. 59).

Essa categorização foi feita a partir dos objetivos específicos da pesquisa para compor três categorias referentes aos aspectos da dinâmica familiar que os pais reproduzem em suas famílias, às circunstâncias que se apresentam mais destacadas no sentido da reprodução de comportamentos, pensamentos e sentimentos por parte dos pais na atual conjuntura familiar e às demandas mais frequentes relacionadas à transmissão psíquica transgeracional.

Portanto, os resultados foram evidenciados em eixos de discussão diante do que foi coletado nos processos selecionados como objeto de estudo, que serão apresentados e elucidados a seguir com a contribuição das literaturas existentes sobre este tema.

\section{ANÁLISE E DISCUSSÃO DOS RESULTADOS}

\subsection{A história das famílias}

A partir dos dados existentes nos laudos psicológicos e relatórios sociais dos processos judiciais analisados para esta pesquisa, entende-se necessário apresentar, de forma breve, a história das nove famílias que compuseram a amostra da pesquisa. É importante esclarecer que os termos utilizados para compor a história dos casos, tais como negligência e abandono, foram retirados dos documentos analisados.

\section{Caso 1}

O acolhimento se deu por negligência física de seus pais. Dos quatro menores, duas eram do gênero feminino e dois do gênero masculino. Uma das filhas adolescente engravidou e um dos outros dois filhos iniciou o uso de substâncias psicoativas. O 
pai dos menores fazia uso de álcool e sua infância foi perpetuada por violência física por seus genitores, o que transferiu para a sua relação com os filhos e a esposa; inclusive havendo episódios de agressão mútua entre o pai e uma das filhas. A mãe não demonstrava qualquer envolvimento ou responsabilidade com a proteção e o cuidado dos filhos, negligenciando os cuidados básicos de limpeza e higiene, assim como a ausência de preocupação com alimentação. Seu discurso expressava que a culpa pela desestruturação familiar estava restritamente no alcoolismo do pai.

\section{Caso 2}

Durante a infância da mãe, seu genitor fazia abuso de álcool e agredia fisicamente sua genitora e seus irmãos. Esta mãe possui três filhos e estava grávida novamente, em um relacionamento instável, com violência conjugal e uso de substâncias psicoativas. Ela foi diagnosticada com doença psiquiátrica e teve três tentativas de suicídio. Seu primeiro relacionamento foi permeado por violência e abuso de substâncias psicoativas pelo genitor do primeiro filho, sendo que este está sob a guarda da avó paterna. O segundo foi entregue à adoção e o terceiro é a criança alvo do processo.

\section{Caso 3}

A família foi atendida pela Secretaria de Assistência Social em 2009, por denúncias de alcoolismo da genitora e agressões físicas contra as crianças, três ao total. A família mudou-se para outro estado e o processo foi extinto à época. Ao retornar a Joinville, a dinâmica familiar permanecia a mesma. A mãe tem histórico de violência física e alcoolismo por parte de sua genitora. Ela reproduzia as agressões sofridas no tratamento e relação com seus filhos. O relacionamento com o pai das crianças era marcado pela violência conjugal, sendo que ambos faziam uso abusivo de álcool.

\section{Caso 4}

O pai teve sua infância permeada por agressões, abandono e negligência de seus genitores e faz uso de substâncias psicoativas desde o início da adolescência. As agressões e a negligência foram transpostas para a relação com sua filha e há indícios de violência psicológica com a sua atual companheira, que também utiliza substâncias psicoativas. A mãe da adolescente teve uma infância com características muito próximas a do pai. Em relação à sua filha, demonstra não entender a necessidade de rotina quanto à alimentação, aos estudos, à higiene e ao sono saudável. Aliado a isso, relata ter diversos relacionamentos afetivos e sexuais paralelos ao com o pai, que frequentam sua residência e tem contato direto com a filha. Por tais motivos, a mãe e a filha transitavam entre a moradia com o pai e a casa da avó, sem qualquer estabilidade. 


\section{Caso 5}

A infância da mãe contou com alcoolismo e violência intrafamiliar por parte de seu genitor e resultou na separação de seus pais posteriormente à sua adolescência. Também houve negligência e abandono materno, situações de abuso sexual infantil por parte do padrasto e do avô paterno, com histórico de acolhimento institucional. A genitora da mãe, ou seja, a avó das crianças desse processo, também teve histórico de negligência e abandono materno, e violência paterna. O pai das crianças deste caso fazia uso abusivo de álcool, sua dinâmica familiar continha violência intrafamiliar e histórico de acolhimento dos filhos por negligência e violência conjugal. Seus filhos, duas meninas e um menino, passaram pelo acolhimento institucional duas vezes.

\section{Caso 6}

A mãe traz o relato de abandono materno, tendo sido criada pela avó. Houve envolvimento familiar com drogas e relata o suicídio do genitor e do padrasto. Ela faz uso de álcool e tentou cometer suicídio três vezes. Seus filhos, que se encontram acolhidos, são de dois relacionamentos distintos, mas ambos marcados por violência intrafamiliar e uso de substâncias psicoativas por parte dos pais.

\section{Caso 7}

Durante a infância, a mãe vivenciou o uso abusivo de álcool e negligência por parte do genitor, e também o falecimento de sua genitora. Esta mãe era casada com o pai da filha mais nova e na dinâmica familiar houve situações de uso de substâncias psicoativas, tráfico de drogas, violência psíquica, física e abuso sexual infantil por parte do padrasto contra as enteadas. O acolhimento dos dois filhos se deu por identificação de negligência.

\section{Caso 8}

A mãe, em sua infância, sofreu rejeição e abandono materno, tendo sido criada pela avó. O pai também foi rejeitado por sua genitora após o nascimento do seu irmão mais novo — num total de três irmãos—-, sofreu abandono psíquico e também passou a morar com a avó. A dinâmica familiar destes pais em relação a seus filhos, dois adolescentes, apresenta abandono físico e psíquico das crianças, violência física, uso de substâncias psicoativas e negligência.

\section{Caso 9}

A mãe é adolescente e estava acolhida institucionalmente. Sua genitora possui 12 filhos e não exercia a guarda de nenhum deles, sendo inclusive destituída do poder familiar 
de alguns. Seu genitor possui histórico de dependência química e violência contra seus filhos, o que também fez parte do processo de acolhimento. O pai da criança teve sua vida perpetuada pelo abandono materno e negligência paterna, foi preso duas vezes e não demonstrou interesse em recuperar sua filha.

\subsection{A vivência da herança}

Diante da análise dos documentos referentes aos processos de Destituição do Poder Familiar, pode-se observar que todas as nove famílias analisadas apresentaram aspectos da reprodução da dinâmica familiar antecessora e, dessa forma, sinalizam a transmissão psíquica transgeracional.

Por se tratar de situações de negligência, abandono, violência e desamparo estão relacionadas à transmissão sem a possibilidade de elaboração do que foi herdado, ou seja, há uma reprodução do comportamento e da dinâmica familiar. De acordo com o levantamento dos dados, em alguns processos a reprodução da dinâmica familiar está mais evidente, como demonstrado no laudo psicológico do Caso 1, analisado conforme o trecho a seguir.

A mãe continua na sua posição de vitimização, pois obtém ganhos emocionais, por exemplo, ela não precisa se responsabilizar pelos filhos, pois culpabiliza o pai, perpetuando a dinâmica do caos, da negligência e da violência física e psíquica. Ela conta que seu pai também era alcoólatra, que agredia sua mãe, que seu pai quebrava tudo em casa e no outro dia limpava. (...) A mãe reproduz no seu relacionamento, o que viveu na sua família de origem, inclusive projetando a culpa no companheiro, assim como sua mãe projetava em seu pail. (Caso 1, p. 1, 1s. 17-24)

Segundo a avalição psicológica, a mãe do Caso 1 vivenciou em sua infância situações de violência intrafamiliar, essa situação traumática não foi elaborada, então em seu casamento ocupa o mesmo lugar vivenciado por sua genitora e reproduz o mesmo padrão de comportamento. Piva (2006) coloca a respeito da transmissão psíquica transgeracional que o ponto central não é apenas o trauma, mas a impossibilidade de elaboração que provoca uma memória traumática que funciona como fixação de experiência e dificulta a produção de novas significações.

No Caso 6 sobressaem apenas alguns sinais que indicam a existência da transmissão psíquica transgeracional, porém sem clareza, conforme apresentado no laudo psicológico: "(...) A mãe não fazia uso de drogas ilícitas, apenas álcool e teria tentado suicídio por três vezes. [...] O pai menciona que a família dela tem envolvimento com

As citações extraídas das transcrições dos processos são indicadas pelo número do caso, pela indicação da(s) página(s) e da(s) linha(s) e pela formatação em itálico. 
assaltos, drogas, etc., (...) Ele não teve certeza se foi o genitor ou padrasto da mãe que cometeu suicídio com veneno" (Caso 6, p. 7, ls. 20-29).

Diante do exposto, a questão das drogas e do suicídio pode ser indício da possibilidade de transmissão psíquica transgeracional. O suicídio é vivenciado por esta mãe de duas maneiras: quando o genitor/padrasto comete o suicídio e, após, quando ela realiza suas tentativas de suicídio. O trauma, para Piva (2006), é um acontecimento intenso na vida do sujeito, que o incapacita de reagir de forma adequada e, dessa maneira, produz um transbordamento emocional que provoca efeitos patológicos na psique, como as tentativas de suicídio desta mãe.

No Caso 5, a força da herança foi transmitida por duas gerações, o que evidencia o quanto o abandono e a dinâmica familiar desestruturada foi constituinte da subjetividade dos integrantes dessa família. Conforme consta nos relatórios, a mãe das crianças em tela teve sua infância marcada pelo alcoolismo e pela violência intrafamiliar por parte de seu genitor, negligência e abandono materno, situações de abuso sexual infantil e histórico de acolhimento institucional. Sua genitora também vem de um histórico de negligência e abandono materno e de violência paterna. $\mathrm{Na}$ dinâmica familiar das crianças em tela existe alcoolismo por parte do pai, violência intrafamiliar e histórico de acolhimento de seus filhos por negligência e violência física.

Segundo Palieraqui (2014), "as vivências da mãe, também são frutos de um passado ancestral que vão se manifestar nos cuidados que ela terá com seu filho" (p. 16). Nesse sentido, diante da transmissão psíquica transgeracional apresentada por essa família, pode-se observar os múltiplos abandonos maternos que há gerações impedem que se estabeleça uma nova forma de se vincular no presente e de exercer a maternagem, e isso impede a mãe de ser o que Winnicott denomina por mãe suficientemente boa, "ou seja, boa o bastante para que o bebê possa conviver com ela sem prejuízo para sua saúde psíquica. Essa mãe representa o ambiente suficientemente bom, cuja importância é vital para a saúde psíquica do ser humano em devir" (Nasio, 1995, p. 186).

Essa transgeracionalidade do abandono materno está relacionada ao que Freud denomina por desamparo, que se refere ao estado do bebê que depende inteiramente do outro para a satisfação de suas necessidades e, desde modo, revela-se impotente para realizar a ação adequada para acabar com a tensão interna (Laplache e Pontalis, 1992). Esse outro, ou seja, a mãe, atenderá a necessidade do filho pela continuidade daquilo que ela vivenciou em seu desamparo inicial, que demarcou e a estruturou psiquicamente de tal forma que a mãe pode colocar seu filho em situação de desamparo semelhante à vivenciada por ela. 


\subsection{As demandas}

As demandas dos processos judiciais e as circunstâncias que envolvem essa dinâmica estão relacionadas às formas de violência intrafamiliar que existem em todos os processos analisados, sendo que oito processos tiveram a demanda relacionada à violência física. Dois casos estão relacionados à violência entre os genitores, sem envolver a criança/adolescente nas agressões, e seis casos envolvem agressões físicas contra as crianças.

O Caso 1 apresenta a transmissão referente à violência,

Observamos ainda uma perpetuação do comportamento agressivo entre os integrantes da família. O pai sofreu agressões quando era pequeno, hoje agride seus filhos e já é agredido pela filha mais velha, sinalizando uma transgeracionalidade da violência intrafamiliar (Caso 1, p. 1, 1s. 7-10).

De acordo com Belsky (1980), existem estudos que apontam que pais que tiveram uma educação severa ou foram vítimas de maus tratos na infância apresentam maior probabilidade de repetir essa experiência com seus filhos. Então, o herdado passa a ser a perpetuação da violência física, como nos oito casos em que o ciclo de violência ultrapassa as gerações. Conforme o exposto no Caso 1, a filha, que também é agressora, denota que a violência está sendo vivenciada por ela, não só como vítima, mas como aprendiz dessa dinâmica familiar, ou seja, o ciclo de violência está a caminho de mais uma geração.

A respeito da negligência, cinco processos obtiveram essa demanda, como demonstrado no Caso 8.

Os genitores e a família tanto materna quanto paterna têm muitos conflitos, que datam da infância de ambos. Dinâmica familiar conflituosa perpetuada ao longo dos anos que resultou no abandono tanto físico quanto psíquico das crianças em tela. (Caso 8, p. 9 , ls. 24-26)

A negligência também é uma forma de abandono em que os genitores estão presentes, mas não proporcionam à criança o afeto e os cuidados necessários, um abandono físico e psíquico em relação ao filho, como suscita Gomide (2003). Nesse sentido, em relação aos casos em que houve negligência observou-se que quatro estão relacionados a um abandono físico por parte dos pais em relação ao filho, como por exemplo, ausência de higiene, ausência de acompanhamento médico em prol da saúde e do bem-estar deles. Também houve dois casos que estão relacionados a um abandono psíquico em relação ao afeto e amparo dos pais ao filho.

Em oito dos nove casos a demanda dos processos de Destituição estava relacionada ao uso de substâncias psicoativas por parte dos genitores, predominantemente 
o abuso do álcool. Porém, também ficou explicito em três casos o uso da maconha, em um caso, a cocaína, e um caso, o crack. Conforme apresentado no trecho do laudo psicológico do Caso 3.

A mãe relata que fazia uso contínuo de bebidas alcoólicas, mas nega que permaneça fazendo. No entanto se contradiz ao ressaltar que no dia anterior a entrevista havia tomado uma cerveja com a nora. Ao ser questionada sobre o motivo de beber comenta que é por raiva, demonstrando vários sentimentos que necessitam ser trabalhados. (...) Ela vem de um histórico familiar de agressões e alcoolismo por parte de sua genitora, foi perceptível que isso influencia suas ações como genitora hoje. Ambos não conseguem perceber a gravidade dos fatos e também demonstram dificuldades em se perceber, não possuem perspectiva de futuro, provavelmente por toda a história pregressa. (Caso 3, p. 2, 1s. 22-36)

Da mesma forma como no Caso 3, os outros sete casos evidenciam o uso de substâncias psicoativas pelos pais como uma fuga em relação a seus conflitos e têm relação com as formas de violência intrafamiliar como, por exemplo, a negligência, a violência física e a violência sexual.

Nesse sentido, a partir das contribuições de Freud em relação ao desamparo, explanada por Palieraqui (2014), entende-se que na situação de desamparo inicial vivenciada, em que a necessidade de proteção também não for atendida pela figura paterna, ficando assim, o sujeito sem suporte, acarretará em um vazio diante dessa necessidade de proteção. De tal modo que o sujeito buscará mais tarde outras formas de atender essa necessidade, ou seja, de preencher esse vazio, uma delas pode ser através do uso de substância psicoativa, como evidenciado nos oito casos. A presença da substância na vida do sujeito está atrelada também a uma fragilidade psíquica, logo, a droga passa a ser a fonte de proteção e de preenchimento para esse pai ou essa mãe.

Existiram, ainda, três demandas únicas que apareceram em apenas um caso. A primeira demanda se refere à violência sexual do Caso 7 .

A adolescente relatou que desde os 13 anos de idade sofria violência sexual praticada pelo padrasto, e que o mesmo acontecia em relação às suas irmãs. Segundo a adolescente, a mãe tinha conhecimento da situação, mas não teve nenhuma atitude protetiva em relação às filhas. (Caso 7, p. 8, 1s. 14-18)

A demanda de abuso sexual infantil está atrelada a uma negligência materna, a mãe teve sua infância marcada pelo falecimento de sua genitora e devido ao uso abusivo do álcool por parte do genitor, a negligência paterna. Na situação vivenciada em relação a seus filhos ela reproduz o padrão de comportamento de seu pai, assume um comportamento negligente em relação aos filhos e se coloca em uma postura de vítima ao culpabilizar a filha adolescente. Conforme evidenciado nos relatórios, "a mãe nega 
qualquer possibilidade de ter havido violência, de qualquer tipo, do padrasto contra os filhos dela e culpabiliza a adolescente pelos conflitos familiares" (Caso 7, p. 24, ls.10-12).

A mãe utiliza o mecanismo de defesa do ego denominado por "negação", de acordo com as contribuições teóricas de Anna Freud, que é a relutância em aceitar um fato que perturba o ego, como as violências praticadas pelo padrasto contra seus filhos. O sujeito tem tendência a "devanear" sobre determinados eventos e nega que eles aconteceram. Da mesma maneira que a mãe também utiliza o mecanismo de defesa denominado por "projeção", que é o ato de atribuir a algo externo, no caso à filha adolescente, as qualidades, os sentimentos ou as intenções que se originam na própria pessoa (Fadiman e Fragner, 2004). Dessa forma, a mãe projeta a culpa em sua filha adolescente e, a partir de seus mecanismos de defesa, a mãe assume uma postura de negligência e abandono em relação a seus filhos.

No Caso 2 há uma demanda que se refere a uma adoção direta, que vai contra o que é estabelecido por lei.

A criança foi acolhida no Abrigo devido prática de adoção direta, em que a mãe entregou a filha, por duas vezes, para um casal de terceiros, bem como pelas possíveis ocorrências de violência física entre os genitores, e suspeita de uso de álcool e outras drogas por parte do genitor. (Caso 2, p. 3, 1s. 01-08)

Trata-se da prática da adoção direta que também está atrelada ao abandono materno. Esta mãe possui três filhos e está grávida: seu primeiro filho está sob a guarda da avó paterna, o segundo foi entregue a adoção e o terceiro é a criança em tela. Retomando o conceito de Winnicott, exposto por Nasio (1995), a mãe deste caso está envolvida em seus conflitos psíquicos e reproduz o padrão de comportamento herdado de sua genitora, que também não maternou seus filhos e, dessa forma, os abandonou — ou seja, não desempenhou a função materna e não se tornou uma mãe suficientemente boa para seus filhos.

No Caso 9, a demanda do acolhimento se referiu ao histórico familiar dos genitores, que eram adolescentes, sendo que a mãe estava em uma instituição de acolhimento, devido à Destituição do Poder Familiar de seus pais.

A mãe tem origem em uma família em que sua genitora, teve 12 filhos e não exerce a guarda de nenhum deles, sendo inclusive destituída do poder familiar de alguns. Seu genitor possui histórico de dependência química e diversas violências contra os filhos. A Adolescente engravidou com 13 anos, após fugir do acolhimento institucional e passar a conviver com o pai da criança. (Caso 9, p. 11, 1s. 18-22)

Nesse caso em específico, a transgeracionalidade pode ser analisada em função do próprio processo de Destituição do Poder Familiar e ao acolhimento institucional 
vivenciado pela adolescente. Como esclarece Mullahy (1978) ao discorrer a respeito da compulsão da repetição em que o sujeito é compelido a repetir uma experiência anterior, mas, o significativo é que a experiência original nunca lhe propiciou qualquer prazer, nem sua reedição.

De tal modo, aqui a adolescente traz uma repetição da Destituição do Poder Familiar em relação a seu filho. Dessa forma, sinaliza a transgeracionalidade, pois o abandono e o acolhimento institucional fizeram parte de sua constituição psíquica e, apesar de ser uma mãe adolescente, proporcionou à sua filha a vivência de acolhimento institucional devido à falta de estrutura e rede de amparo familiar, seja por sua família ou a do pai da criança.

\section{IMPACTOS NA PSIQUE FRENTE À TRANSMISSÃO PSÍQUICA TRANSGERACIONAL}

Diante do exposto ao longo das análises, pode-se observar que as formas de violência intrafamiliar e o abandono das crianças e adolescentes nas dinâmicas familiares resultam na perpetuação do sofrimento. Nesse sentido, é imprescindível compreender a constituição psíquica do sujeito diante da transmissão desse sofrimento. Para tal compreensão se faz necessário abordar a relação estabelecida entre o papel parental e a constituição do sujeito.

Segundo Mullahy (1978), são os pais que primeiramente representam o poder externo que posteriormente, será o papel exercido pelo superego². Seu desenvolvimento é, fundamentalmente, um processo de identificação em que a criança aprende e adota o comportamento e a atitude dos pais. Na configuração familiar desses casos de Destituição do Poder Familiar, o que é passado para a criança é o ciclo de violência intrafamiliar, do abuso de substâncias psicoativas, do abandono e do sofrimento. Então, isso começa a fazer parte da constituição psíquica desse sujeito que, sem a possibilidade de elaboração do que foi transmitido e vivenciado, há grande chance de reprodução do mesmo padrão de comportamento, ou seja, aquele filho adota o comportamento e a atitude de seus pais.

Cabe ressaltar que em oito processos a demanda foi relacionada às formas de violência intrafamiliar e uso de substâncias psicoativas, predominantemente o álcool. Assim, quando investigado o histórico dos pais em questão, identifica-se que em três casos os pais vivenciaram em sua infância situações de violência de seu genitor contra sua genitora e uso abusivo de álcool por parte deste. Um caso em que a ge-

Superego é uma entidade psíquica ao mesmo tempo destrutiva (que internalizou a violência da libido) e estruturante (que malgrado seu caráter, faz parte inevitavelmente da estrutura do aparelho psíquico). (Homrich, 2008, p. 196) 
nitora agredia os filhos e fazia o uso abusivo de álcool e cinco casos que se referem ao abandono materno, tendo os pais em tela sido criado por terceiros, como avós ou pela figura paterna.

Conforme Mullahy (1978) "o superego da criança não é realmente edificado segundo o modelo dos pais, mas pelo 'superego' dos pais que recebe idêntico conteúdo, torna-se o veículo de tradição e de valores que, por esse processo têm sido transmitidos de geração em geração" (p. 73). Diante de tal assertiva, é a partir do conteúdo que é recebido desse pai que o sujeito se constitui. Desse modo, em relação aos casos de Destituição do Poder Familiar, foi identificado que o que é passado está relacionado à violência, ao uso de substâncias psicoativas e ao abandono, assim, o que se recebe dos pais é a perpetuação de mais sofrimento, tal qual vivenciado durante gerações.

Há, em oito casos, mães que buscaram figuras masculinas semelhantes ao seu pai, ou seja, um homem agressivo e abusivo, que faz uso de substâncias psicoativas. Aqui, tem-se a premência do conceito freudiano do complexo de Édipo, qual seja, um conjunto organizado de desejos amorosos e hostis que a criança sente em relação aos pais. Ainda seguindo Mullahy (1978), quando o complexo de Édipo desaparece é que a criança deve abandonar sua intensa dedicação emocional pelos pais e encontrar uma compensação ou substituto para essa perda. A partir da compreensão de conflitos mal resolvidos oriundos do complexo de Édipo e da realidade dos casos, a configuração familiar e psíquica do sujeito identificada nos casos analisados faz com que a mãe busque uma figura masculina semelhante ao seu pai e, diante da perpetuação do ciclo de violência, torna-se conivente com isso.

A constituição psíquica desses pais pode proporcionar e impulsionar a reprodução da violência e do abandono, pois eles em determinado momento de sua infância também vivenciaram o desamparo por seus genitores. Como evidenciado nesses cinco casos em que os pais tiveram a vivência do abandono materno desde muito cedo em sua constituição psíquica, bem como de forma indireta nos outros quatro casos, o que se tem são marcas que não podem ser elaboradas, seja pela negação, projeção ou pela necessidade, e devido a isso, hoje, essas crianças de outrora, reproduzem a negligência e o abandono na vida dos seus próprios filhos.

\section{CONCLUSÕES}

Os processos judiciais de Destituição do Poder Familiar tratam de dinâmicas familiares desestruturadas, em que a perpetuação da violência e do abandono se fazem presentes, bem como a reprodução das posturas e vínculos das famílias de origem e o impacto delas no desempenho do papel parental. 
A existência de indícios da transmissão psíquica transgeracional em todos os processos analisados reforça a necessidade e a importância da Psicologia diante dessa ação. Trata-se de uma transmissão em que não houve a possibilidade de elaboração daquilo que foi herdado e, devido a isso, a reprodução do abandono, da violência e do abuso se apresenta como eminente. Foi possível perceber o quanto as partes envolvidas não têm consciência de sua herança e o quanto isso influencia seu papel parental, tanto na execução dele quanto na omissão.

De acordo com os processos analisados é notável que a possibilidade de mudança dessa dinâmica se dá quando se instaura o processo de Destituição do Poder Familiar e seus filhos são encaminhados a uma instituição de acolhimento ou para a família ampliada. De tal modo, destaca-se a dificuldade das famílias em realizar a mudança na dinâmica familiar e sustentá-la, o que acaba repercutindo na perda do Poder Familiar ou em situações de (re)acolhimento institucional de seus filhos, ou seja, de uma nova intervenção do Estado na família. Diante disso, a família deve ser vista em sua singularidade e a constituição psíquica dos pais e a dinâmica familiar deve ser compreendida.

Sendo assim, a Psicologia Jurídica, ao compreender o sujeito em sua singularidade, tende a compreender as implicações psíquicas que envolvem a transmissão psíquica transgeracional. A partir dessa vertente, a Psicologia Jurídica pode enriquecer a compreensão da problemática dessas famílias que estão vivenciando a Destituição do Poder Familiar, e compreender sua singularidade, sem culpabilizá-los, mas sim, com o objetivo de problematizar as questões em prol do bem-estar da criança e/ou adolescente.

Nesse sentido, ao concluir esta investigação, as conjunturas e os dilemas familiares analisados por intermédio dos casos utilizados como exemplares de uma realidade tão perversa apontam a urgência de estudos nessa área, que possibilitem a escuta e o entendimento dos profissionais da Psicologia e do Direito que trabalham com essa demanda. Portanto, seria importante estudos que buscassem compreender as situações que envolvem o (re)acolhimento da criança, bem como o impacto social da transmissão psíquica transgeracional.

\section{REFEREENCIAS}

Bardin, L. (1995). Análise de conteúdo. Lisboa: Edições 70.

Belsky, J. (1980). Child maltreatment: an ecological integration. American Psychologist, 35, 320-335. DOI: 10.1037/0003-066X.35.4.32

Cellard, A. (2008). A análise documental. In: J. Poupart, et al. (Orgs.). A pesquisa qualitativa: enfoques epistemológicos e metodológicos. Petrópolis: Vozes. 
Cesca, T. B. (2004). O papel do psicólogo jurídico na violência intrafamiliar: possíveis articulações. Psicologia e Sociedade, 16(3), 41-46.

Day, V. P., Teller, L. E. de B., Zoratto, P. H., Azambuja, M. R. F. de, Machado, D. A., Silveira, M. B. Blank, P. (2003) Violência Doméstica e suas diferentes manifestações. Revista de Psiquiatria, 25(Suppl. 1), 9-21.

Dias, M. B. (2006). Manual de Direito das Famílias. São Paulo: Editora Revista dos Tribunais.

Eiguer, A. (1998). A transmissão do psiquismo entre gerações: enfoque em terapia familiar psicanalítica. São Paulo: Unimarco Editora.

Fadiman, J., Fragner, R. (2004). Personalidade e crescimento pessoal. Porto Alegre: Artmed.

Ferreira, L. A. M. (2004). O promotor de justiça frente à institucionalização da criança e adolescente em entidade de abrigo e destituição do poder familiar. Revista Justiça, 1-9.

Franco, M. L. (2008). Análise de Conteúdo. Brasília: Liber Livros.

Gomide, P. I. C., Guimaraes, A. M. de A., Meyer, P. (2003). Análise de um caso de extinção do poder familiar. Psicologia Ciência e Profissão, 23(4), 42-47.

Homrich, A. C. B. (2008). O conceito de superego na teoria freudiana (tese de doutorado). Universidade de São Paulo, São Paulo, Brasil.

Huss, M. T. (2011). Psicologia Forense: Pesquisa, Prática Clínica e Aplicações. Porto Alegre: Artmed.

Laplanche, J., Pontalis, J. (1992) Vocabulário da Psicanálise. São Paulo: Martins Fontes.

Lemaire J. G. (2003) Les transmissions psychiques dans le couple et la famille: l'intrapsychique, l'intersubjectif et le transpsychique. Dialogue - Recherches cliniques et sociologiques sur le couple et la famille, 2e. trimester, 160(52), 17-26.

Mullahy, P. (1978). Édipo: Mito e Complexo - uma crítica da Teoria Psicanalítica. Rio de Janeiro: Zahar Ed.

Nasio, J. D. (1995) Introdução às obras de Freud, Ferenzi, Groddeck, Klein, Winnicott, Dolto, Lacan. Rio de Janeiro: Zahar Ed.

Palieraqui, R. E. B. (2014). O Desamparo e a Transmissão Psíquica. Revista Conexões Psi, 2(2), p. 15-32.

Pereira, C. M. da S. (2004). Instituições de Direito Civil. Rio de Janeiro: Forense.

Piva, A. (Ed). (2006). Transmissão transgeracional e a clínica vincular. São Paulo: Casa do Psicólogo.

Rehbein, M. P., Chatelard, D. S. (2013) Transgeracionalidade Psíquica: Uma revisão de literatura. Fractal: Revista de Psicologia, 25(3), 563-583. 
Santos, S. S. (2007). Mães de meninas que sofreram abuso sexual intrafamiliar: reações maternas e multigeracionalidade. (dissertação de mestrado). Universidade Federal do Rio Grande do Sul, Rio Grande do Sul, Brasil.

Silva, D. M. P. (2003). Psicologia jurídica no processo civil brasileiro: a interface da psicologia com direitos nas questões de família e infância. São Paulo: Casa do Psicólogo.

Torres, A. C. F., Costa, C. L. N. A., Silva, B. V. O., Santos, D. A., Filho, E. T. S., Campos, J. C., Andrade, K. D. G. De Silva, M. S. Rios, N. M. R. (2012). Destituição do Poder Familiar. Cadernos de Graduação Ciências Humanas e Sociais, 1(14), p. 219-222.

Tostes, A. F. (2007). Criança em situação de abandono: um diálogo entre a Psicanálise e o Direito (dissertação de mestrado). Universidade de São Marcos, São Paulo, Brasil.

\section{Outras referências}

Código Civil Brasileiro e legislação correlatada. (2008). Brasília. Senado Federal.

Estatuto da Criança e do Adolescente. (2014). Brasília. Congresso Nacional. 